\title{
Bilinguismo na educação dos e para os surdos: uma discussão reflexiva sobre a política educacional e linguística
}

Bilinguism in education for and for the deaf: a reflective discussion on educational and language policy

\author{
Marisa Dias, LIMA (UFU/FACED) ${ }^{1}$ \\ Lazára Cristina da, SILVA (UFU/FACED) ${ }^{2}$
}

\section{RESUMO}

Atualmente a Educação dos e para os Surdos se depara com vários impasses existentes nas políticas educacionais e linguísticas que apresentam diferentes práticas discursivas, conduzidos por uma reflexão equivocada. Desta forma é necessário haver uma intervenção sobre a política pública brasileira a fim de estabelecer a relação entre a Inclusão Escolar e Educação dos Surdos sendo efetivada na formação, estruturas e ações pedagógicas em uma perspectiva bilíngue. No entanto, o presente artigo visa apresentar vários direcionamentos aos professores e demais profissionais envolvidos com estudos e discussões teóricos acerca da Educação dos e para os Surdos com o objetivo de promover a compreensão e apreensão das correlações e tensões existentes entre a legislação brasileira inclusiva, sua criação e desenvolvimento nas instituições públicas envolvidas a fim de que possa ser agrupado na política educacional e linguística na Educação dos Surdos e assim efetivar a Inclusão Escolar dos estudantes Surdos.

Palavras-Chave: Política Educacional, Política Linguística, Surdos, Libras, Português L2

\begin{abstract}
Nowadays the Education of and for the Deaffaces several impasses existing in educational and linguistic policies that present different discursive practices, led by a mistaken reflection. Thus, it is necessary to have an intervention on Brazilian public policy in order to establish the relationship between School Inclusion and Education of the Deaf, being made effective in the formation, structures and pedagogical actions in a bilingual perspective. However, this article aims to present several directions to teachers and other professionals involved in theoretical studies and discussions about Education for and for the Deaf, with the objective of promoting the understanding and apprehension of the correlations and tensions existing between the Brazilian inclusive legislation, its creation and development in the public institutions involved so that it can be grouped in educational and linguistic politics in the Education of the Deaf and thus effect the School Inclusion of Deaf students.
\end{abstract}

Keywords: educational policy, linguistic policy, Deaf, Libras, Portugueses L2

\footnotetext{
1 Universidade Federal de Uberlândia, Uberlândia, Minas Gerais, Brasil. Faculdade de Educação. ORCID: https://orcid.org/0000-0001-9805-6499; marisalima.ufu@gmail.com

2 Universidade Federal de Uberlândia, Uberlândia, Minas Gerais, Brasil. Faculdade de Educação. ORCID: https://orcid.org/0000-0002-4647-8785; lazara_cristina@hotmail.com
} 


\section{Contextualizando a Educação dos Surdos}

A discussão acerca da Educação dos Surdos tem ganhando maior ênfase recentemente, porém, desde sempre, a educação tem conduzido à reflexão do desenvolvimento humano em diferentes âmbitos, sejam eles em aspectos de uma reflexão cognitiva, quanto ao afetivo, social, cultural e ao relacional. A instituição escolar, por seu turno, coloca-se como lugar privilegiado de vivências significativas, não só pelos conhecimentos que ela ensina e veicula, mas também, pela possibilidade de os mesmos instigarem as construções que a ela proporciona, por meio de trocas entre os diferentes sujeitos que a compõe, independentemente dos lugares que ocupam e, principalmente, pela sua funcionalidade em instrumentalizar o sujeito, entendido, como um ser social, que estabelece múltiplas relações para produzir e reproduzir sua vida em sociedade.

Baseando-se nessa percepção acerca do papel da instituição escolar na vida do sujeito, a educação brasileira, desde a Constituição Federal de 1988 assumiu o desafio de possibilitar o direito de todos à educação, com a fundamentação de garantir o acesso e a permanência de todas as pessoas na escola, inclusive as pessoas Surdas ${ }^{3}$ que ao longo dos anos, foram encarados pelas sociedades em geral, como um ser limitado e incapacitado, por não compartilhar a mesma língua dos outros que residem no mesmo ambiente social, pelo fato de as pessoas Surdas, no caso do Brasil, adotarem a Libras como seu meio de comunicação.

A partir desse entendimento, apresentou-se no Brasil a implementação de políticas públicas aglutinando propostas e projetos de governos e de instituições no âmbito da educação, visando adequar as especificidades dos estudantes Surdos à realidade cotidiana. Nesse processo, várias discussões foram repensadas e formuladas novamente, com o intuito de contribuir na adequação das ações para inserir a formação dos estudantes Surdos da mesma forma que são aplicados na educação dos estudantes ouvintes numa perspectiva da política atual - a educação inclusiva ${ }^{4}$.

No entanto, este estudo amparara-se na abordagem histórico-cultural, que parte do pressuposto essencial de que as pessoas Surdas se constituem nas relações humanas transformando-se e transformando-as. Agrega-se ao pressuposto de que, em um estudo científico, direta ou indiretamente, as possibilidades de desenvolvimento das pessoas Surdas na vida social, ocorrem mediadas por meio da cultura em que vive (GÓES, 2010). A partir desta compreensão, é possível apreender as inúmeras

\footnotetext{
${ }^{3}$ A terminologia de "pessoas Surdas" utilizado nesta pesquisa se refere às pessoas que se sintam como um ser "capacitado" que tem dentro de si a cultura surda e utiliza-se a língua de sinais como seu meio de comunicação aprendidos dentro do grupo da comunidade Surda que é o sujeito de estudo desta pesquisa.

${ }^{4}$ Quando falamos em inclusão escolar ou em educação inclusiva, tratamos do direito de TODOS, sem exceção, a educação escolar.
} 
prerrogativas discorridas sobre os direitos das pessoas Surdas com a educação/ensino bilíngue vista e dita como o ideal para a efetivação da política de educação dos e para os $\operatorname{Surdos}^{5}$.

No entanto, a necessidade do uso da Libras como base de instrução e a sua importância para o desenvolvimento dos estudantes Surdos, foi o pressuposto que fundamentou os estudos dedicados a evidenciar as peculiaridades dos processos educacionais deste grupo específico. Essas demandas organizadas e tomadas como bandeiras pelos movimentos sociais representantes das comunidades Surdas culminaram, consequentemente, na promulgação da Lei $n^{0} 10.436 / 2002$ que dispõe sobre a Libras, posteriormente, regulamentada pelo Decreto ${ }^{0} 5.626 / 2005$ que também foi apoiada com o art. $18^{\circ}$ da Lei $\mathrm{n}^{\mathrm{o}} 10.098$, de 19 de dezembro de 2000 .

Assim, estamos diante de um impasse, uma vez que as orientações das políticas públicas brasileiras afirma garantir aos estudantes Surdos o acesso ao conhecimento, no qual o mesmo precisa ser feito por meio da Libras - ou seja, o ensino precisa acontecer com professor bilíngue e/ou com o apoio de intérprete, sendo assegurada por uma política linguística, que tem, ainda, como foco o uso da Libras como meio de instrução e o ensino do Português como segunda língua a ser mediado em Libras, mas mantendo-se centrado a língua da nação.

Enfim, diante dos pontos abordados acima, acerca da definição do processo de significação, esta pesquisa se baseará na compreensão do discurso sob uma perspectiva da Educação dos e/ou para os Surdos com referência no embasamento teórico no que tange a Política Educacional e Política Linguística na Educação dos e para os Surdos.

Diante das questões apresentadas, demarcamos como problema deste estudo: No Brasil, desde a criação do decreto $n^{0} 5.626$, no ano de 2005, está se configurando a construção de políticas das e para as pessoas Surdas, no campo educacional e linguístico? Como essas políticas estão sendo propostas e recebidas na sociedade brasileira?

Visando conseguir responder essas questões baseadas na delimitação de uma discussão reflexiva deste estudo, determinamos como objeto de estudo, uma pesquisa transversal dos referenciais teóricos e legais que fundamentam as políticas educacionais e políticas linguísticas públicas brasileiras, no tocante à Educação dos e para os Surdos, para compreender e apreender as correlações e tensões existentes entre a legislação brasileira inclusiva, sua criação e desenvolvimento nas instituições envolvidas com a educação dos e para os Surdos, entre eles a Instituição de Ensino Superior e as Instituições de Surdos, no

\footnotetext{
${ }^{5}$ Utiliza se nesta pesquisa o termo "Educação dos e para os Surdos" por tratar de uma educação mais abrangente em diferentes contextos que se destina a Educação das pessoas Surdas agrupadas em um só. Pois se entende que há distinção de discussão referente a Educação dos Surdos: promover tipos de ensino específico as pessoas Surdas; Educação de Surdos: tipo de ensino recebida; Educação para Surdos: se agrupa a diferentes tipos de sistema de ensino que deve prevalecer para as pessoas Surdas.
} 
período de 2005 a 2017. Tendo por objetivo identificar e analisar: a) as diretrizes gerais da legislação educacional brasileira, na temática da política educacional referente a formação geral e na educação dos e para os Surdos, elementos da política linguística das e para as pessoas Surdas; b) nos documentos nacionais, a inserção da preocupação com a formação do Surdo e do ouvinte no ensino de/em Libras e Português como segunda língua para a escolarização das pessoas Surdas.

Portanto, é importante deixar claro que este estudo investigativo tem como compromisso promover uma discussão reflexiva de como a inclusão escolar, como um processo político educacional e linguístico, se intensifica na sociedade atual. A inclusão escolar está sendo problematizada, aqui, como uma suposta forma de incluir socialmente os sujeitos que enfrentam as exclusões e as discriminações advindas das distintas formas de deficiências e, também, das diferenças sociais, econômicas, culturais, etc.

Nesse sentido, tratar a inclusão escolar como uma prática relevante na atualidade significa colocar em jogo uma série de questões - seus deslocamentos, suas rupturas, suas continuidades. Assim, os desafios que esse tema coloca é o de procurar pensar em como os significados são construídos na realidade educacional, isto significa, também, pensar nos cuidados necessários ao examiná-lo.

Ressalta-se que nesta pesquisa, o estudante Surdo, pessoa Surda, sujeito Surdo referem se, conforme o Decreto $n^{0} 5.626 / 2005$, que regulamenta a Lei $n^{0} 10.436 / 2002$, em seu art. $2^{\circ}$, àqueles que compreendem e interagem com o mundo "por meio de experiências visuais, manifestando sua cultura principalmente pelo uso da Língua Brasileira de Sinais - Libras” (BRASIL, 2005, p.01). Assim, a centralidade da concepção escolhida e defendida para o termo "Surdo" está na Libras e nas experiências visuais, não na deficiência auditiva e/ou sensorial.

\section{Política Educacional Brasileira e a Educação de Pessoas Surdas}

A Política Pública Nacional de Educação no Brasil tem por objetivo buscar instituir os sistemas educacionais que consideram a igualdade e a diferença como um elo indissociável e constitutivo para a sociedade. Mediante a perspectiva a se adotar nos sistemas educacionais, em 1990, foi construída uma nova política educacional na qual a Educação é tomada como um direito de todos, atualmente, baseando se numa política da Educação Inclusiva. Porém, as dificuldades ainda persistem aos estudantes, principalmente aos Surdos, pois os profissionais envolvidos no processo educacional ao empregar a promoção de uma ação pedagógica, a estrutura de forma mais explícita com os processos normativos que não atende as suas especificidades em razão de características culturais, sociais e linguísticas, entre outras.

Tais mecanismos são estruturantes do modelo tradicional de educação, não incorporando formas mais apropriadas ao trabalho com os estudantes Surdos, somam-se, ainda, as carências de materiais e de 
recursos pedagógicos, a ausência de um espaço formativo que promova à busca de condições adequadas à sua promoção pessoal e profissional, ampliando a sua qualificação e conhecimento geral, específico e pedagógico a fim de aplicá-los na sala de aula. Porém, a realidade dessa prática, segundo estudos de Harrison \& Lodi (1997); Skliar (1997); Lunardi (1998); Lacerda (2006); Perlin (2008), entre outros, se demonstram insatisfatórios.

Para adequar a realidade educacional vivida após 1990, foi promulgada diferentes leis no sentido de promover Política Educacional para as pessoas Surdas e, para tanto, foi preciso adotar algumas equiparações necessárias, entre elas, destaca-se a adequação do campo legal. A LDB nº 9.394/1996; PCNs para a Educação Especial (1999), o PNE (2001), Lei da Libras nº 10.436/2002; Decreto nº 5.626/2005; PNEEPEI (2008); e o Relatório sobre a Política Linguística na Educação Bilíngue - Libras e Língua Portuguesa (2014). Nesse contexto, os estudantes Surdos fazem parte da população com deficiência e possuem o direito a uma escolarização de ensino bilíngue/Pedagogia Surda, devendo acontecer no espaço da escola comum.

Tais ensinos a serem transversalizados aos estudantes Surdos se apresentaram escassos, pois não possuem ações afirmativas aplicadas na Educação dos e para os Surdos, tanto nas ações pedagógicas, quando nas estruturas e formação dos profissionais envolvidos que acabou por instigar várias discussões e mobilizou os movimentos Surdos, em prol de uma educação que contemple as suas especificidades linguístico-culturais, pois o movimento compreende que a escola comum não proporciona um ambiente linguístico favorável, pois nele não há uma comunidade de sinalizantes, com pares Surdos e professores bilíngues que possibilitem a construção de uma identidade Surda como minoria linguística e cultural. Para o movimento Surdo, a educação de ensino bilíngue/Pedagogia Surda deve ocorrer "em ambiente linguístico natural, o qual pode ser criado em classe ou escola bilíngue de e para surdos" (FENEIS, 2011, p. 3).

A partir dessa percepção e discussão, foi proposto, nesse processo, as diversas reivindicações do movimento Surdo posteriores à Política, assim como a busca por um espaço de discussão junto ao MEC resultaram na criação de um Grupo de Trabalho (GT) designado pelas Portarias nº 1.060/2013 e nº 91/2013 do MEC/SECADI que elaborou os Subsídios publicados no início de 2014, tomadas como os documentos mais atuais e recentes os quais visam orientar a construção de uma política educacional bilíngue, preferencialmente, em escolas e classes bilíngues, com tempo integral dos estudantes na escola, considerando as suas especificidades culturais e linguísticas.

Apresenta-se o nivelamento do primeiro documento promulgado com a Lei voltada à promoção de qualidade de ensino de e das pessoas Surdas, a LDB n 9.394/1996, que regulamenta toda a educação 
nacional, na qual a educação, em consonância com a Constituição Federal de 1988, é entendida como um direito de todos, independentemente de suas condições físicas, emocionais e intelectuais.

Como forma de consolidar essa premissa se modificou, também, a compreensão da educação especial, cuja oferta passou a ocorrer como uma modalidade de ensino, oferecida, preferencialmente, na rede regular educacional, disponível desde a educação infantil até a educação de ensino superior, superando o modelo de educação especial substitutiva ao ensino regular.

O PNE (2001) estabeleceu o ensino de Libras ao estudante Surdo, o apoio aos familiares e à comunidade escolar, o uso da Libras, como disciplina. A Libras seria também contemplada no currículo de cursos de formação de professores em todos os níveis para atender os estudantes Surdos nas escolas.

Com a aprovação da Lei da Libras em 2002, a educação dos Surdos foi melhor estruturada, pois houve o reconhecimento da Libras como língua das comunidades Surdas brasileiras garantindo o seu uso no processo educacional. Como desdobramento dessa ação, foi promulgado o Decreto ${ }^{0}$ 5.626/2005 que prevê ações que promovem a educação de pessoas Surdas apoiada em uma política linguística: Libras como primeira língua e o português na modalidade escrita como segunda língua.

Nesse sentido, a PNEEPEI, em 2008, em consonância com a Educação Inclusiva propõe o delineamento de diversas ações educacionais que visam primeiro superar a lógica da exclusão de quaisquer pessoas no ambiente escolar sendo estendida à sociedade.

Considerando os pontos observados acima, foram implantadas ações educacionais de acordo com o Relatório do GT (2014) na política pública de Educação dos e para os Surdos, com a finalidade de quebrar o estigma e a tensão existentes na política pública vigente e que por muitos anos vêm produzindo práticas discursivas e não discursivas na educação de ensino bilíngue/Pedagogia Surda para Surdos, constituindo-se em jogos de saber-poder entre os discursos que, segundo Lodi (2013), partem de “princípios político-ideológicos distintos”. Portanto, o relatório foi criado a fím de orientar a construção de uma política educacional bilíngue, preferencialmente, nas escolas bilíngues que considerem "as especificidades culturais e linguísticas dos sujeitos surdos”, sendo a sua temática sido recentemente pautada na discussão e construção de políticas educacionais em nosso país.

Ressalta-se que segundo Ball (1997), nenhuma política é neutra, pois se insere em um campo de representações codificadas e decodificadas, engendradas, em determinado contexto histórico e espaço geográfico, de uma forma complexa e multifacetada, por meio de conflitos, lutas e correlações de forças.

A Educação dos e para os Surdos e suas ações pedagógicas, por muitos séculos, demonstraram que as políticas educacionais sempre foram elaboradas sob uma perspectiva dos ouvintes e não dos Surdos baseando-se sempre no discurso ouvintista, no qual os Surdos, quase sempre, são ignorados e excluídos do grupo de reuniões e discussões sem quaisquer possibilidades de opinar e, muitos deles, são 
desvalorizados como sujeitos, que têm sua língua e cultura própria, que podem contribuir a partir de suas capacidades inerentes à sua formação e experiências construídas pela sua diferença que tem as suas especificidades e particularidades linguísticas, que enriquecem a sua cidadania (MOURA, 2000).

A vinculação da educação dos Surdos com a educação especial tem estado presente, historicamente, configurando-se, quase sempre, em um campo muito contestado pelas pessoas envolvidas, principalmente pela comunidade Surda, pelo fato da política, segundo Skliar (1998), na maioria das vezes, ser voltada para a perspectiva do discurso ouvintista não dos seus pares.

A definição da forma como a ação da educação especial ocorrerá sobre a educação dos e para os Surdos pode ser encontrada desde a Constituição Federal de 1988, que em seu Art. 208, determina como dever do Estado a garantia do Atendimento Educacional Especializado, às pessoas com deficiência, preferencialmente, na rede regular de ensino (BRASIL, 1988). O mesmo documento destaca que a educação precisa ser vista como um "direito de todos e dever do Estado e da família, promovida e incentivada com colaboração da sociedade, visando o desenvolvimento da pessoa, seu preparo para o exercício da cidadania” (BRASIL, 1988, p. 49).

\section{Política Linguística e a Educação dos e para os Surdos}

As políticas linguísticas têm sua ação em todo o mundo, acompanhando movimentos políticos, sociais e, também, os culturais (CALVET, 2007). As políticas públicas sociais englobam as políticas de educação que, por sua vez, incluem as políticas linguísticas e estas estão interligadas com os direitos, com a cultura e com o Estado (CRISTOFOLI, 2010).

Segundo Calvet (2007), a política linguística é um conjunto de escolhas conscientes referentes às relações entre língua(s) e vida social, o planejamento linguístico: a implementação prática de uma política linguística. Não importa que grupo possa elaborar uma política linguística: fala-se, por exemplo, de "políticas linguísticas familiares" (p. 145).

Partindo disso, alçamos uma discussão sobre a Política Linguística, quando há uma preocupação e um planejamento entre à relação de poder e as línguas ou, mais propriamente, entre as decisões políticas sobre línguas e seus usos na Educação dos e para os Surdos, tendo por enfoque a formação dos Surdos e ouvintes envolvidos, sejam eles ingressantes ou profissionais com os debates e argumentos que nos instigam a um estudo reflexivo e a discussão sobre a necessidade e a importância da implementação dessa política linguística na Educação dos e para os Surdos que incita as ações pedagógicas e estruturais, juntamente o seu uso e difusão.

Introduzo a discussão ocorrida no Brasil que desde o período colonial tentava-se reforçar o pressuposto de cultura e língua únicos. Estes ainda persistem em alguns lugares, uma vez que é 
naturalizada a prática de se impor uma cultura monolíngue, procurando ocultar o plurilinguísmo existente, bem como generalizando uma propagação da ideia de que se fala uma mesma língua portuguesa nos quatro cantos do país, e que, portanto, todos se entendem. No entanto, nem é preciso ser estudioso da língua para perceber que essa cultura de "língua única" é equivocada. Tal possibilidade se concretiza apenas enquanto uma única língua oficial da República Federativa do Brasil, a língua portuguesa (Constituição Federal/88, art.13) ${ }^{6}$.

Partindo-se desse pensamento, observa-se que, no caso das pessoas Surdas que têm a Libras como a sua primeira língua, devem ser estimuladas a utilizar e aprender também a Língua Portuguesa que é a língua oficial do país residente em diversos contextos, sendo enfatizada no parágrafo único da Lei $\mathrm{n}^{\circ}$ 10.436/2002 (BRASIL, 2002), de que a Libras não poderá substituir a Língua Portuguesa, que, para os Surdos, é uma segunda língua; e o Decreto $n^{\circ}$ 5.626/2005 ainda reforça que a Língua Portuguesa para Surdos deve ser ofertada e adquirida em modalidade escrita.

Essa determinação da Lei $\mathrm{n}^{\mathrm{o}} 10.436 / 2002$, consequentemente, acaba por privar e/ou limitar o acesso pleno das pessoas Surdas na Libras, distorcendo a percepção da política linguística bilíngue Libras e Português, pois a Língua Portuguesa se coloca em posição desigual com a Libras em diferentes contextos sociais perpetuando uma cultura monolíngue. Segundo Calvet (2007), a percepção sobre a cultura monolíngue provoca um impedimento e embate histórico e educacional, seja ele explícito ou não; são situações que poderiam inibir as possibilidades de participação política dos cidadãos brasileiros falantes de outras línguas.

Assim sendo, nas últimas décadas, o Brasil vivencia um crescimento de debates e reivindicações de temáticas ligadas aos aspectos sociais, político, cultural e linguístico. Este último sendo refletido acaloradamente pela comunidade Surda no que tange a Libras, com suas especificidades linguísticas diferentes, espalhadas de norte a sul do país, com o seu status linguístico reconhecido e a ser difundido, sendo ele tanto no espaço escolar quanto no espaço político, cultural, entre outros.

Porém, na realidade, a Libras não é utilizada de fato com o devido status linguístico em determinados ambientes onde as pessoas Surdas frequentam, pois a maioria deles designa a Libras como um acessório para suprir as carências, como é o caso na educação dos e para os Surdos, que ainda não vê as pessoas Surdas cidadãs com suas particularidades linguísticas e, por conseguinte, não as oportunizam a interagir e participar na sociedade em que a Libras deve ser constituída naturalmente entre as pessoas Surdas e ouvintes conforme afirma Quadros (2009, p.11).

O Surdo, como usuário natural da língua, deve estar presente na comunidade, escola,

\footnotetext{
${ }^{6}$ Texto constitucional determina que a Língua Portuguesa é o idioma oficial da República Federativa do Brasil (CF/88, art.13).
} 
universidades para que todos possam identificar-se positivamente e desenvolver a utilização da língua de sinais da forma mais natural possível. A mesma autora também diz que "As festas, os jogos, os campeonatos, as sedes organizadas por surdos são formas de interação social e linguística, que garantiram a formação da comunidade surda brasileira com uma língua própria.

Apesar de a Língua Portuguesa ser a língua oficial do Brasil e a segunda língua dos Surdos, e, por sua vez, a Libras ser a língua materna das pessoas surdas, ambas lhes permitem interagir e participar na sociedade, no entanto, os direitos humanos linguísticos das pessoas Surdas devem ser assegurados no ponto de vista de que, conforme Quadros (2009, p.10,11):

a) Todos os seres humanos têm direito de identificarem-se com uma língua materna(s) e de serem aceitos e respeitados por isso;

b) Todos têm o direito de aprender a língua materna(s) completamente, e escrita (pressupondo que a minoria linguística seja educada na sua língua materna);

c) Todos têm o direito de usar sua língua materna em todas as situações oficiais (inclusive na escola);

d) Qualquer mudança que ocorra na língua materna deve ser voluntária e nunca imposta.

Contudo, em todo o território nacional, esse processo precisa ser iniciado em todos os ambientes, onde o mesmo necessita oferecer os seus resultados significativos, a fim de se criarem mecanismos de divulgação, aquisição, aprendizagem e, principalmente, o uso da Libras, sob pena de não se construir um status linguístico favorável para a Libras.

Entende-se por status linguístico, uma língua de prestígio, fomentados em línguas oficiais, de trabalho, nacional, no caso da Libras que é correlacionada com a língua de sinais. Stokoe, apud Quadros \& Karnopp (2004) comprovou a sua complexidade, na medida em que, assim como as línguas orais, as línguas de sinais possuem regras gramaticais e léxico que permitem a expressão dos conceitos, os abstratos e a produção de uma quantidade infinita de sentenças.

Paterno (2007, p.77-79) afirma que o status linguístico da Libras está sendo planificado em sua imensidão, pois:

[...] conforme os surdos se qualificam estes terão outra postura perante a sociedade e esta perante estes. Surdos reconhecidos implica em ter-se mais professores qualificados para o ensino das crianças surdas, maior abertura por parte dos pais para o aprendizado da Libras e a sua utilização em casa. Possibilidade de crianças surdas terem professores surdos e de circularem nos mais diversos lugares e encontrarem pessoas que saibam Libras. Assim vê-se que há uma grande possibilidade de mudança do status linguístico da Libras, passando de uma língua excluída com uso quase que apenas entre os surdos e nas associações de surdos para uma língua de ampla veicularidade nos diversos espaços de nossa sociedade.

Por conseguinte, entende-se que é preciso articular uma fomentação das políticas para o ensino bilíngue, que ainda está longe de um panorama satisfatório, no que tange as políticas linguísticas na 
Educação dos e para os Surdos. Pouca atenção tem sido dada a esse assunto, restringindo se muitas vezes, a projetos que têm data para iniciar e terminar, além de que, a maioria, concentra-se em certa região limitando a participação das demais regiões.

Partindo-se do contexto da Educação dos e para os Surdos reconhece-se que houve vitórias e avanços das políticas públicas decorrentes da criação da Lei n ${ }^{\circ}$ 10.436/2002 e da promulgação do Decreto $n^{\circ} 5.626 / 2005$, que regulamentam e criam o debate da política linguística, porém, os mesmos documentos vêm carregando de intencionalidades de interesses próprios que, só mais tarde se fizeram mais perceptíveis à comunidade Surda pois foram elaborados e publicizados numa percepção dos ouvintes estruturado em um discurso romântico com a finalidade de convencer o público beneficiado de sua exatidão, na prática docilizando e resinificando as reivindicações manifestadas.

Neste cenário, pode-se pensar que esta estratégia política além de, ou, antes de, estar preocupada com a inserção das pessoas Surdas na rede de ensino, está criando estratégias de convencimento de que um movimento de educação inclusiva, proposta pelos governantes, é possível além de ser a melhor alternativa para todos. Esses movimentos são definidos por Foucault (1992, p. 172) como governamentalidade ${ }^{7}$ ao afirmar que fizemos parte de "uma sociedade controlada pelos dispositivos de segurança".

Entretanto, quando se verifica a intenção de intervenção do Estado sobre as línguas, onde o mesmo impõe as modificações em sua forma e status, consequentemente, nos instiga para uma visão existente relativa ao registro governamental e de idiomas, aliadas às situações linguísticas, uma vez que dentre suas funções, destaca-se o exercício de um poder.

No entanto, ao discutir a presença do status linguísticos da Libras em todos os ambientes, apesar da mesma ser adotada e utilizada massivamente pelas pessoas usuárias desta língua, a Libras não alcança o mesmo status da Língua Portuguesa, que é respaldada pela emenda constitucional que a tem como a língua oficial do país, portanto, é essencial destacar que a Libras é uma língua reconhecida, mas não tem o mesmo patamar de prestígio do status linguísticos, aportados em todos os espaços que as pessoas Surdas frequentam, como por exemplo, nem todos os lugares como os hospitais, bancos e outros locais públicos promovem o acesso da Libras.

No que tange ao conceito de língua baseado na perspectiva saussuriana, o mesmo consiste em observá-la como o fato social, mais especificamente, como um sistema convencional adquirido pelos sujeitos durante o convívio social. (TARALLO, 2005). Desse modo, a língua sofre variações que podem

\footnotetext{
${ }^{7}$ Se seguirmos na perspectiva da governamentalidade, entendemos que este é um processo individual e social. É o governo agindo sobre o sujeito que se subjetiva a partir dos significados que consegue produzir para si. O sujeito se mostra agente neste processo juntamente com o social. É como se passássemos pelos processos de convencimento e colaboração.
} 
ser definidas em diversos modos de se dizer a mesma coisa em ambientes iguais ou diferentes. Calvet (2004, p.67) define a linguística como o estudo das comunidades humanas através da língua, e reafirma que "as línguas existem para servir aos homens e não os homens para servir à língua". O autor reforça que " a língua é um dos elementos primordiais de uma cultura, em outras palavras, a atividade linguística contínua é um elemento constitutivo das identidades culturais de um povo, no caso, o povo surdo com sua comunidade surda (CALVET, 2004, p.67, Grifo nosso).

Além deste, Calvet (2002, p. 145) enfatiza que é o papel do estado elaborar políticas linguísticas, pois é ele quem detém “o poder e os meios de realizar esse planejamento e de pôr em prática as escolhas linguísticas" (CALVET, 2002, p. 145).

Sob a pressuposição destes aspectos, a partir dos anos 90, os estudos nessa área começaram a surgir, ganhando atenção maior do poder público em vários países. O que resultou na promulgação da Declaração Universal dos Direitos Linguísticos, explicitada em 1996, durante a Conferência Mundial de Direitos Linguísticos, em Barcelona. Esse documento foi assinado pelo Brasil apenas em 2006, ano em que também se registra a criação do primeiro e único programa de Pós-Graduação em Linguística, com linha de pesquisa em política linguística, na Universidade Federal de Santa Catarina (UFSC), embora o Instituto de Investigação e Desenvolvimento em Política Linguística (IPOL) ${ }^{8}$ venha se dedicando ao tema desde 1999.

Se definirmos política linguística como o faz Calvet (2007) consideraremos que se trata das grandes decisões referentes às relações entre as línguas e a sociedade: em que língua o Estado funcionará e se relacionam com os cidadãos, em que língua(s) a educação e os serviços culturais serão oferecidos, que variedade de língua será usada, se as outras línguas faladas pelos cidadãos serão reprimidas, reconhecidas ou promovidas.

Ao se propor discutir a Política Linguística da Libras e Língua Portuguesa como segunda língua, tendo em vista, esta temática ser o objeto de estudo e discussão desta pesquisa, é necessário reivindicar igualmente uma Planificação Linguística. Segundo Oliveira (2009, p.9) o termo "política linguística" é inseparável de outro, o conceito de "planificação ou planejamento linguístico", que se refere justamente

\footnotetext{
${ }^{8}$ IPOL - Instituto de Investigação e Desenvolvimento em Política Linguística - é uma instituição sem fins lucrativos, de caráter cultural e educacional, fundada em 1999, com sede em Florianópolis, Santa Catarina, Brasil, que representa os interesses da sociedade civil. Mais informações no link:

http://e-ipol.org/sobre-o-ipol/

${ }^{9}$ Os conceitos de política e planificação linguística foram primeiramente sistematizados na década de 1960 pelo linguista Einar Haugen (1966), sendo assim articulados por Oliveira (2004, p.38) Política linguística é o conjunto de decisões que um grupo de poder, sobretudo um Estado (mas também uma Igreja ou outros tipos de instituições de poder menos totalizantes), toma sobre o lugar e a forma das línguas na sociedade, e a implementação destas decisões". Planificação linguística são propostas para modificar a realidade linguística - do status de uma língua em relação a outra, ou de aspectos da sua forma - e se referem ao futuro da relação entre as línguas. Um processo de planificação linguística posta em marcha passa a ser uma política linguística (p. 38, grifos no original).
} 
ao percurso para a implementação das políticas, sua transformação em realidade. De todo modo, entre o desejo de que os indivíduos utilizem a língua e os passos concretos para que uma população inteira a utilize existem elementos de planejamento: ações concretas, sistêmicas, financiamento e orçamento, formação de quadros, entre outros.

[...] a planificação linguística é a política linguística posta em prática. O planejamento é uma atividade humana decorrente da necessidade de se encontrar uma solução para um problema". Ele pode ser completamente informal para uma determinada finalidade, mas pode também ser organizado e deliberado ou até mesmo em ser executado por indivíduos particulares ou um ser oficial. [...] Se o planejamento for bem feito, ele compreenderá etapas tais como a pesquisa extensa de dados, a escolha de planos de ações alternativos, a tomada de decisão e sua aplicação. (CALVET, 2007, p. 21).

A escola é um meio de interação da língua, e que, no contexto de uma identidade e cultura distinta, políticas linguísticas são adotadas para a identificação das variedades linguísticas, bem como, um fator de identificação social. Dessa maneira, a instituição escolar não deveria adotar uma padronização linguística, uma vez que faz parte de um ambiente plurilíngue, neste contexto, entende-se que a escola deve promover aos estudantes Surdos um ambiente que supra todas as interações necessárias.

Referindo-se a situação linguística dos Surdos na instituição escolar Dizeu \& Caporali (2005, p. 584) fazem a seguinte consideração:

Vivemos em uma sociedade na qual a língua oral é imperativa, e por consequência caberá a todos que fazem parte dela se adequarem aos seus meios de comunicação, independentemente de suas possibilidades. Qualquer outra forma de comunicação, como ocorre com a língua de sinais, é considerada inferior e impossível de ser comparada com as línguas orais. Muitos profissionais que trabalham com surdos têm uma visão sobre a língua de sinais como uma forma de comunicação, não atribuindo a ela o status de língua e considerando-a apenas uma alternativa para os surdos que não conseguiram desenvolver a língua oral (Grifo nosso).

Desconstruir esse processo não significa simplesmente determinar os espaços que as línguas passam a ocupar, mas passar por um processo muito maior de reflexão, de (des)estruturação, formação de profissionais, criação de novos espaços de trabalho e, em especial, inversão da lógica das relações. É preciso reconhecer o que representam as línguas para os próprios Surdos. Não basta simplesmente decidir se uma ou outra língua passará a fazer ou não parte do cenário da proposta escolar, mas tornar possível a existência das línguas, reconhecendo-as de fato e constituindo um espaço de negociação permanente.

Calvet (1997) revisa que a ação do Estado sobre as línguas é uma prática muito antiga, porém, a criação de uma política com um estudo prévio, uma planificação e sua execução são práticas recentes. Ao reportar se a Libras, as decisões que foram tomadas pelos governos, ora, para reprimi-las, ora, para 
promovê-las, também são políticas linguísticas que se encontram incipientes para ser implantadas na educação de forma que efetive a formação, neste caso formação dos Surdos e ouvintes. Como exemplo, quando ocorreu em 1880, no Congresso de Milão, que culminou na decisão dos membros presentes, pelo não uso das línguas de sinais na educação dos Surdos e a promoção da língua oral e escrita como a única língua para instrução dessas pessoas, sendo esta utilizada como uma política linguística quando foram empregados pelos governos de diferentes países, que por muitos anos acabou por privar os direitos linguísticos das pessoas Surdas, durante o seu processo de escolarização sem ofertar a planificação linguística adequada e, muito menos, assegurar o seu status linguísticos em todo o espaço escolar.

Ressalta-se que até recentemente, no Brasil, a Libras não era usada no espaço escolar, era uma língua desprestigiada e marginalizada, as lutas da comunidade Surda e de organizações representativas dos Surdos, como a FENEIS, mobilizaram o Estado a mudar a então vigente política linguística presente na comunidade. Pois a efetiva implementação de uma política linguística na Educação dos e para os Surdos depende massivamente do Estado, pois é ele que detém o poder sobre as instituições que possibilitem a implantação de uma política linguística, ao qual se recorre quando se deseja efetivar a política que pudesse de fato promover o uso linguístico da Libras e em seus diferentes contextos.

Apresenta-se abaixo alguns exemplos de como possibilitar a promoção linguística correlacionando os com o Relatório do GT (2014):

a) criar ambientes linguísticos para a aquisição da Libras como L1 e português como L2 por crianças surdas instaurando um programa na qual eles sejam expostos a interações em Libras;

b) prever espaços para aquisição da Libras no espaço escolar contemplando-se com as atividades em Libras que envolvem interação, conversação, contação de histórias, etc;

c) definir a participação das duas línguas na escola em todo o processo de escolarização de forma a conferir legitimidade e prestígio da Libras como língua curricular e constituidora da pessoa Surda; d) fortalecer o ensino da Libras, científica e técnica, com vistas a prover essa Língua de conhecimentos avançados que possibilitem o desempenho de competências e habilidades no plano nacional.

No entanto, hoje, dificilmente se vê a existência de práticas e ações de políticas linguísticas na educação dos e para os Surdos, que favorecem de fato a visibilidade de seu uso linguístico tão centrais, no caso da Libras, utilizada pelas pessoas Surdas como forma de expressão.

\section{Considerações Finais}


Há que se compreender que há necessidade de oferecer visibilidade aos fatores linguísticos nos processos de educação de e para os Surdos, para tal, em primeiro lugar, é necessário a naturalização das questões linguísticas, pois vivemos dentro de uma sociedade majoritária que utiliza a língua portuguesa, na maioria das vezes, por isso, nem sentem a presença e, muito menos, sabe da existência da Libras, como também, a sua necessidade de uso pelas pessoas Surdas.

Quando se priva as pessoas Surdas do uso linguístico da Libras em um determinado contexto consequentemente, sofrerão consequências tais como, apresentação de "problemas cognitivas, sociais e educacionais", como apresenta a Goldfeld (1997, p.31) ao partir-se da pressuposição do Góes (1994, p. 95), ao ditar que "a Língua tem um papel fundamental, como mediadora das interações e da significação do mundo". Pois, entende-se que a Língua é uma construção que promove a transmissão de conhecimentos e da cultura, agregando o seu aprendizado. Posteriormente, esta desenvolverá a sua formação social, podendo, desta forma, leva-los a exercer seus direitos como cidadão. Por isso, segundo Bagno (2003; apud NOVAES, 2010, p.36) a Libras deve ser vista "não só como ferramenta que devemos usar para obter resultados", ela é produtora e transmissora de cultura como acredita a autora Strobel (2008).

Além disso, há o preconceito sobre esta mesma língua, na qual ainda se luta contra ele, mas, a maioria, não sente a discriminação tão efetiva e pouco tematizada pelo fato de que o preconceito linguístico ainda não ser legislado de forma legal dentro da nossa sociedade acaba por generalizar nas pessoas a uma atitude de conformismo ${ }^{10}$.

Em segundo lugar, é que as políticas linguísticas aparecem diluídas dentro de políticas culturais, de políticas educacionais, de políticas de inclusão ou de exclusão, na qual pouco se aparece como uma das funções do estado, embora as mesmas estejam necessariamente presentes na maioria das políticas educacionais e culturais.

O Estado é o principal articulador das políticas linguísticas, portanto, sempre em interação com outras instâncias centralizadora de poder, na qual a presença e os usos das línguas em cada situação é uma questão política e constantemente permeada de conflitos e negociações como Lanes (1980, p. 428) têm apontado, pois, "o fato é que, independentemente da abordagem linguística desejada, as forças políticas econômicas sempre prevalecem sobre as forças linguísticas para se determinar se um grupo definido é capaz ou não de manter lealdade à sua língua materna”. De fato, reproduz-se um padrão recorrente, em estudos de grupos de minorias, vivendo dentro de sociedades oficialmente monolíngues.

\footnotetext{
${ }^{10} \mathrm{O}$ significado do conformismo neste estudo tem por contexto o fato de as pessoas que são sujeitadas a resignação ou a passividade, como resultado de uma pressão real e/ou imaginária de uma pessoa ou grupo. De alguma forma na cultura Surda, aqueles que não-conformistas são considerados "desviantes" ou "insuficiente" e não são muito apreciados pelo grupo que se recusa a resistir.
} 
Por fim, a política linguística, ainda não é vista como política, sendo continuamente questionada em nome dos chamados "princípios técnicos" baseados em decisões técnicas, científicas, aparentemente tomadas pelos linguistas, e não como decisões que instigam as diferentes possibilidades. Em outro momento, quando ora são tomadas pelos governantes, é transpassada em uma visão distorcida propondoas como uma ação opcional na prática na qual as relações de poder destas decisões são apagadas, como se não houvesse outras possibilidades. Por outro lado, a comunidade surda vive se hoje, ainda superficial, um momento privilegiado para as políticas linguísticas, apesar de ser com formato da diversidade, como não vivido em outros tempos na conformação do país.

\section{Referências}

BAGNO, M. Preconceito linguístico. O que é, como se faz. 17. ed. São Paulo: Loyola, 2002. BALL, S. J. Good school/bad School, British. Journal of Sociology of Education. 1997. BRASIL. Constituição da República Federativa do Brasil de 1988. Disponível em: $<$ http://www.planalto.gov.br/ccivil_03/constituicao/constituicao.htm>. Acesso em ago. 2017. . Lei $n^{\circ}$ 9.394, de 20 de dezembro de 1996. Estabelece as Diretrizes e Bases da Educação Nacional. Disponível em: http://www.planalto.gov.br/ccivil 03/leis/19394.htm. Acesso em mai. 2017. . Lei $\mathrm{n}^{\mathrm{o}} 10.098$, de 19 de dezembro de 2000. Estabelece normas gerais e critérios básicos para a promoção da acessibilidade das pessoas portadoras de deficiência ou com mobilidade reduzida, e dá outras providências. Disponível em: http://www.planalto.gov.br/CCIVIL_03/Leis/L10098.htm. Acesso em jul. 2017.

. Lei $\mathrm{n}^{0} 10.172$, de 09 de janeiro de 2001. Aprova o Plano Nacional de Educação e dá outras providências. Disponível em: http://www.planalto.gov.br/ccivil_03/leis/leis_2001/110172.htm. Acesso em jul. 2017.

. Lei $\mathrm{n}^{0} 10.436$, de 24 de abril de 2002. Dispõe sobre a Língua Brasileira de Sinais Libras e dá outras providências. Disponível em: http://www.planalto.gov.br/ccivil_03/leis/2002/110436.htm. Acesso em jun. 2017.

Decreto $n^{\circ} 5.62 \overline{6}$, de 22 de dezembro de 2005. Regulamenta a Lei ${ }^{\circ} 10.436$, de 24 de abril de 2002, que dispõe sobre a Língua Brasileira de Sinais - Libras, e o art. 18 da Lei $\mathrm{n}^{\circ} 10.098$, de 19 de dezembro de 2000. Disponível em: http://www.planalto.gov.br/ccivil_03/ato20042006/2005/decreto/d5626.htm. Acesso em mar. 2017.

Ministério da Educação. Política Nacional de Educação Especial na perspectiva da Educação Inclusiva. Brasília: SEESP, 2008.

CALVET, L. J. Las'politiques lingüísticas. Edicial S.A. Buenos Aires, 1997. Parábola, 2002. . Sociolinguística, uma introdução crítica. Trad. Marcos Marcionilo. São Paulo:

As políticas linguísticas. São Paulo: Parábola Editorial: IPOL, 2007.

CRISTOFOLI, M. S. Políticas de línguas estrangeiras na educação básica: Brasil e Argentina entre avanço, percalços. Tese de Doutorado em Educação. Universidade Federal de Uberlândia, 2010. DIZEU, L. C. T. B.; Caporali, S. A. A Língua de Sinais constituindo o surdo como sujeito. Educação \& Sociedade, 2005.

FOUCAULT, M. Microfísica do poder. Rio de Janeiro: Graal, 1992.

GÓES, M. C. R. de. A Linguagem escrita de alunos surdos e a comunicação bimodal. Tese de Doutorado de Livre Docência. Campinas: FE/UNICAMP, 1994. 
. As contribuições da abordagem histórico-cultural para a pesquisa em educação

especial. In: BAPTISTA, C. R.; CAIADO, K. R.; JESUS, D. M. de (Org.). Educação Especial: diálogo e pluralidade. 2. ed. Porto Alegre: Editora Mediação, 2010.

GOLDFELD, M. A criança surda: linguagem e cognição numa perspectiva sociointeracionista. $2^{\mathrm{a}}$ ed. São Paulo: Plexus Editora, 2002.

HARRISON, K. Marie P.; NAKASATO, R. Q.. Educação universitária: reflexões sobre uma inclusão possível. In: LODI, A.C.B. et al. Letramento e Minorias. Porto Alegre, 2004.

LLANES, F. J. Notes on a social theory for bilingual education in the United States. In: PADILLA, R. V. (ed.) Theory in BILINGUAL EDUCATION. Ethnoperspectives in bilingual education research, Volume II. Bilingual bicultural education programs, Eastern Michigan University, 1980.

LACERDA. C.B.F. de. A inclusão escolar de alunos surdos: o que dizem alunos, professores e intérpretes sobre esta experiência. Caderno Cedes, v. 26, n. 69, p. 163-184, 2006.

LUNARDI, M L. Cartografando Estudos Surdos: currículo e relações de poder. In: SKLIAR, Carlos (Org.). A Surdez: um olhar sobre as diferenças. Porto Alegre: Mediação, 2005. p. 157 - 168. $3^{\mathrm{a}}$ ed.

LODI, A. C. B. Ensino da língua portuguesa como segunda língua para surdos: Impacto na educação básica. In: LACERDA, C. B. F. de; SANTOS, L. F. dos (Org.). Tenho um aluno surdo, e agora?: Introdução à LIBRAS e educação de surdos. São Carlos: EdUFCSCar, 2013.

MOURA, M. C. O surdo: caminhos para uma nova identidade. Rio de Janeiro: Revinter/Fapesp, 2000.

NOVAES, E. C. Surdos: educação, direito e cidadania. Rio de Janeiro: Wak, 2010.

OLIVEIRA, G. M. Línguas como Patrimônio Imaterial. 2009. Disponível em: http:/www.ipol.org.br/. Acesso em jun. 2017.

PATERNO, U. A política linguística da rede estadual de ensino em Santa Catarina em relação à educação de surdos. Dissertação. Mestrado em Linguística, Universidade Federal de Santa Catarina, 2007.

PERLIN, G.T. Prefácio. In: QUADROS, R. M. de; PERLIN, G. (Org.). Estudos Surdos II. Petrópolis: Arara Azul, 2008. p. 9-13.

QUADROS, R.M. de. Políticas linguísticas e bilinguismo na educação de surdos brasileiros. In: Ana M. Carvalho. (Org.). Linguística luso-brasileira. 1 ed. Madrid: IBEROAMERICANAEDITORIAL VERVUERT. v. 2, p. 215-235. 2009.

QUADROS, R. M. de \& KARNOPP, L. Língua de sinais brasileira: estudos lingüísticos. ArtMed. Porto Alegre, 2004.

SKLIAR, C. Sobre o currículo na educação dos surdos. Espaço, Rio de Janeiro, 1997. . Os estudos surdos em educação: problematizando a normalidade. In: SKLIAR, C.

(Org.). A surdez: um olhar sobre as diferenças. Porto Alegre: Mediação, 1998.

STROBEL, K. L. As imagens do outro sobre a cultura surda. 1 ed. Florianópolis: Editora UFSC, 2008. TARALLO, F. A pesquisa sócio-linguística. São Paulo: Ática, 2005.

THOMA; CAMPELLO et. al,. Relatório do Grupo de Trabalho, designado pelas Portarias $n^{\circ} 1.060 / 2013$ e n ${ }^{\circ}$ 91/2013, contendo subsídios para a Política Linguística de Educação Bilíngue - Língua Brasileira de Sinais e Língua Portuguesa. 2014. Disponível em:

http://www.bibliotecadigital.unicamp.br/document/?down=56513. Acesso em mai. 2016. 